\title{
Mapping urban living standards in developing countries with energy consumption data
}

\author{
Felix Agyemang, Sean Fox*, Rashid Memon
}

June 2021

\begin{abstract}
Data deficits in developing countries impede evidence-based urban planning and policy, as well as fundamental research. We show that residential electricity consumption data can be used to partially address this challenge by serving as a proxy for relative living standards at neighbourhood scale. We illustrate this by combining infrastructure and land use data from Open Street Map with georeferenced data from $\sim 2$ million residential electricity meters in the megacity of Karachi, Pakistan to map median electricity consumption at block level. Equivalent areal estimates of economic activity derived from high-resolution night lights data (VIIRS) are shown to be a poor predictor of living standards by comparison. We argue that electricity data are an underutilised source of information that could be used to address empirical questions related to urban poverty and development at relatively high spatial and temporal resolution.
\end{abstract}

Keywords: Urbanization; Electricity; Living standards measurement; Night lights; Energy poverty; Pakistan

JEL Classification: C18, C81, O18, R12

\footnotetext{
${ }^{*}$ Corresponding author. School of Geographical Sciences, University of Bristol, University Road, Bristol BS8 1SS, United Kingdom (sean.fox@bristol.ac.uk). Agyemang: School of Geographical Sciences, University of Bristol (felix.agyemang@bristol.ac.uk). Memon: Mushtaq Ahmad Gurmani School of Humanities \& Social Sciences, Lahore University of Management Sciences (rashid.memon@lums.edu.pk). We are grateful to Saba Asif and K-Electric for the opportunity to explore the research potential of this data. We thank Sidra Adil at the Collective for Social Science Research (CSSR) for outstanding research assistance, as well as Haris Gazdar, Zaheer Gazdar and Hussain Bux Mallah for important insights. Helpful feedback was provided by Ayesha Ali and Abu Baker Memon at LUMS, Silvia Redaelli at the World Bank, and Yanos Zylberberg at Bristol University. This research was funded by the UK Economic \& Social Research Council (ES/R009848/1) and International Growth Centre (PAK-20050).
} 


\section{Introduction}

Rapid urban population growth in low and middle-income countries (LMICs) is contributing to the 'urbanization of poverty' (Ravallion et al., 2007). Yet the true scale and nature of this challenge is unknown as we generally lack accurate and up-to-date data about household conditions in most cities in LMICs. Census data are infrequent and often undercount the urban poor (Carr-Hill, 2013; Lucci et al., 2018; Onda et al., 2019), and traditional household surveys (e.g. Demographic and Health Surveys, or Living Standards Measurement Study data) generally do not have large enough samples to provide representative data for individual cities, let alone smaller areal units such as neighbourhoods. These traditional data sources are therefore of limited use in rapidly growing cities where policymakers need timely and spatially explicit information to support decision-making and efficient resource allocation. Given that virtually all projected population growth in coming decades will be absorbed by urban areas in low- and middle-income countries (United Nations, 2018), urban data deficits are a significant obstacle to global poverty alleviation and development efforts (Baker \& Schuler, 2004).

To address this problem, we draw inspiration from studies that use energy consumption as a proxy for subnational output (Chen \& Nordhaus, 2011; Gibson et al., 2021; J. V. Henderson et al., 2012; V. Henderson et al., 2011) and demonstrate how residential electricity consumption data can be used to provide areal estimates of relative living standards within urban areas in LMICs.

There is growing recognition that access to modern energy-i.e. energy from clean, affordable and renewable sources, such as electricity - should itself be a key indicator of living standards independent of other factors (González-Eguino, 2015; Nussbaumer et al., 2012; World Bank, 2017), and was included as Goal 7 of the UN Sustainable Development Goals. However, domestic energy consumption is also strongly correlated with traditional measures of living standards, such as income, consumption, and asset ownership. It could therefore serve as a useful proxy in the absence of such data. Electricity consumption data are also a uniquely promising source of proxy information given that an estimated $97 \%$ of urban residents worldwide have access to electricity (World Bank, 2017, p. 18).

We use the megacity of Karachi in Pakistan to illustrate this potential. Karachi reflects many of the challenges facing urban planners and policy makers in LMICs: it is growing and changing fast, but data deficits obscure the nature of these changes. According to the 2017 census, Karachi has a population of 16 million, but this is widely believed to be an underestimate and concerns about the accuracy of the census have led to a supreme court case ("MQM-P Seeks SC Directive for Fresh Census" 2020). Moreover, even basic population statistics and socioeconomic data have yet to be published as of March 2021. Nationally representative survey data are available every few years, but due to the sampling methodology these cannot be used to make inferences about household conditions within individual cities such as Karachi—only the urban sector in general.

To develop a nuanced understanding of the spatial distribution of living standards in Karachi we use data from a nationally representative survey in Pakistan to establish the association between household electricity consumption and living standards in the urban sector generally. We then use a bottom-up approach to generate a of map of Karachi with 'organic' spatial units for analysisessentially blocks and neighbourhoods - using Open Street Map data. Drawing on data from $\sim 2$ million residential electricity meters in the city, we estimate median monthly electricity consumption in kilowatt hours $(\mathrm{kw} / \mathrm{h})$ for each block. Finally, we estimate energy consumption for each block using night lights data - a common proxy for regional energy consumption in the literature-and compare results. The maps provide a snapshot of relative living standards in the city at a high spatial resolution. 
Our analysis makes two key contributions to the literature. First, we demonstrate that electricity data can be used to generate high-resolution areal estimates of living standards in urban areas in the absence of traditional sources such as census or administrative data- a common challenge in LMICs. These small area estimates could be used to significantly improve the efficiency of social policy targeting in cities (Elbers et al., 2007). Second, we show that even relatively high-resolution night lights data (VIIRS) on their own are not suitable for this purpose in the urban context.

In the next section we review the literature related to household energy consumption and living standards and establish the link between urban electricity consumption and living standards in Pakistan empirically. In section III we describe the process of estimating energy consumption from electricity and night lights data. Section IV compares consumption estimates from each source. Section V concludes with a discussion of applications, limitations and directions for further research.

\section{Electricity consumption and urban living standards}

A positive association between household energy consumption and living standards is now wellestablished in the literature. Empirically, the extent to which improved access to modern energy can drive improvements in household living standards is a subject of ongoing research and debate (Bernard, 2012; Dinkelman, 2011; Grogan \& Sadanand, 2013; Lee et al., 2020a, 2020b). However, there is abundant evidence from experimental and observational studies that increases in income and assets are associated with increased total energy consumption (from all fuel types) at the household level. Importantly, rising living standards are associated with increased consumption of electricity in particular as households move up the 'energy ladder' (away from traditional biomass fuels) and diversify their 'energy portfolios' (see Van Der Kroon et al., 2013).

For example, a randomized controlled trial in rural India found that cash and asset transfers increased total household fuel consumption and specifically electricity for lighting (Hanna \& Oliva, 2015). Similarly, Nawaz \& Iqbal (2020) used a Regression Discontinuity Design to measure the causal impact of a cash transfer program on fuel choice and expenditure in Pakistan and found a significant impact on monthly per capita fuel expenditure. These findings are consistent with observational studies based on survey data in wide range of urban contexts, including Brazil (De Martino Jannuzzi \& Schipper, 1991), China (Cao et al., 2019; Zhou \& Teng, 2013), Ghana (Sakah et al., 2019), India (Filippini \& Pachauri, 2004), Mexico (Gertler et al., 2016) and South Africa (Ye et al., 2018). The link between income and electricity consumption (as opposed to other fuels) is particularly strong in urban areas where access is near universal: globally, an estimated $97 \%$ of urban residents have access to electricity (World Bank, 2017).

The strength of the income-energy consumption association varies by country and context (weather and socio-cultural factors are also significant) but is highly consistent within each context. Electricity consumption data may therefore be a useful proxy for household living standards in urban areas in the absence of detailed data on household income, assets or expenditure. It has the added advantage of being measurable in near real-time, which may be particularly useful for policymakers seeking information about the household-level impacts of economic shocks in LMICs.

There are two primary channels linking income to residential electricity consumption, both mediated by household appliances — particularly those associated with lighting, cooling, heating, washing, and refrigeration, which constitute a substantial proportion of total household electricity consumption. Rising income increases electricity consumption (a) directly due to greater use of existing appliances in the home (intensive margin), and (b) indirectly through the adoption and use of new appliances (extensive margin). Across countries there is roughly an S-shaped relationship between 
income and ownership of energy-consuming appliances, with low levels of ownership among at the bottom end of the income distribution, a sharp increase at context specific thresholds and a plateau in the upper deciles (Wolfram et al., 2012). In low- and middle-income countries, the adoption and use of new appliances is a strong indicator of improvements in household living standards and can be observed indirectly with electricity consumption data.

The links between income, appliance ownership and electricity consumption are evident in Pakistan. To illustrate this, we use data from the urban sub-samples of two rounds of the nationally representative Household Income and Expenditure Survey (HIES) conducted by the Pakistan Bureau of Statistics in 2015-16 $(\mathrm{n}=8805)$ and $2018-19(\mathrm{n}=15,934) .^{1}$

First, to assess the relationship between appliance ownership and electricity consumption we constructed a household Electrical Appliance Index (EAI) from the 2018-19 round of the HIES survey, weighting each appliance by the intensity of its energy requirements and expected daily usage. ${ }^{2}$ We then calculated average monthly electricity consumption in kilowatt hours $(\mathrm{kw} / \mathrm{h})$ for each household from monthly expenditure on electricity using government notified tariff information from the respective rounds of the Economics Survey of Pakistan (see Appendix A1 for detail). ${ }^{3}$

Importantly, electricity consumption varies by geography and season, and the HIES data were collected over the course of a year. This could introduce a significant source of measurement error given that respondents are asked only about the past months' electricity expenditure. Despite efforts to account for this in the sampling procedure, we find some geographic bias in the season of enumeration. Twenty percent of the sample was enumerated in the summer, when demand for electricity intensive cooling appliances is highest, and five of 29 districts were not enumerated in the summer at all. Since poor households' electricity consumption would not change by much in summer and richer households' electricity consumption would (due to a higher probability of owning air coolers or air conditioning units), this geographical imbalance may introduce a downward bias in estimates. ${ }^{4}$

Figure 1 presents boxplots showing the association between household electricity consumption and the EAI, with households clustered into electricity consumption deciles. ${ }^{5}$ We use household electricity consumption deciles (as opposed to continuous values) to be consistent with our empirical approach used later in the paper. As expected, the association is positive (despite concerns about potential measurement error), with median values for the EAI increasing most abruptly in the lowest and highest deciles_-consistent with previous findings. The Electricity Appliance Index explains 37 percent of the variation in household electricity consumption once family size and dwelling size are controlled for in a weighted OLS regression with clustered standard errors (see Appendix A3).

\footnotetext{
${ }^{1}$ The HIES is conducted at regular intervals and generally has around 8000 observations for the urban areas. In 2015-16, an additional component, the Family Budget Survey, was added to the HIES. The purpose of this additional component was to derive weights for rebasing price statistics. The urban sample was therefore roughly doubled to capture high price variation in urban areas.

${ }^{2}$ Asset data used to calculate the index was available only for the 2018-19 round.

${ }^{3}$ Electricity consumption is measured at the household level to maintain consistency with the remainder of the paper which uses household level meter data.

${ }^{4}$ We also note that one district contains no winter observations and a further 3 contain no spring observations.

${ }^{5}$ There are 22 household out of 8500 with an EAI of 0 . These outliers are omitted in Figure 1.
} 
Figure 1. Household electricity consumption \& Electrical Appliance Index in 2018/19

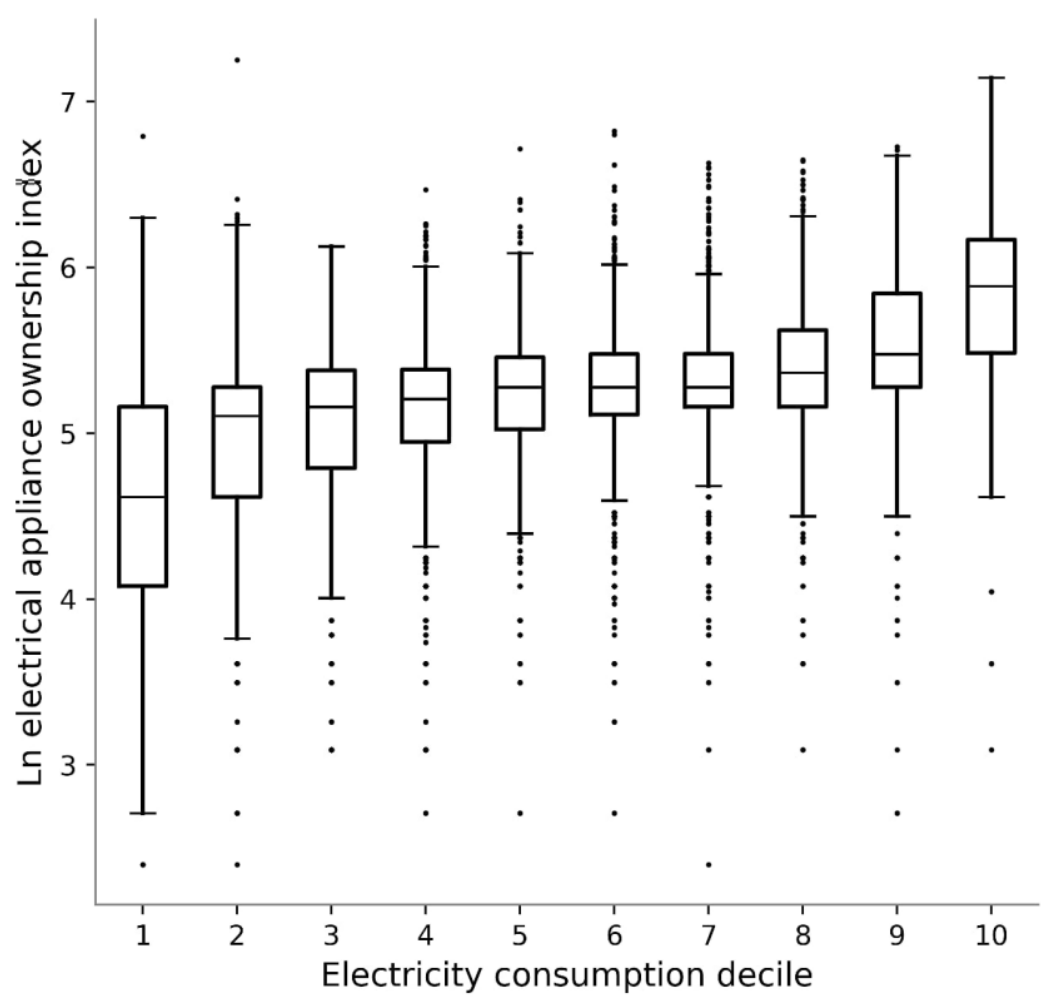

Next, we constructed an index of per capita household expenditure (on non-durables) as a proxy for living standards. ${ }^{6}$ Many countries, including Pakistan, routinely use the HIES (or similar) to estimate consumption-expenditure based poverty lines. Our approach follows this tradition. In this case we used the latter two rounds of the HIES survey to determine whether there is a consistent relationship between electricity consumption and household expenditure. Figure 2 presents boxplots of showing the association between household electricity consumption and per capita expenditure.

While not strictly monotonic ${ }^{7}$ the positive association between expenditure and electricity consumption is clear: higher levels of electricity consumption are systematically associated with higher levels of expenditure-our measure of living standards - across both the 2015-16 and 2018-19 survey rounds. Household level analysis shows that the correlation between per capita expenditure and electricity consumption was 0.5 in 2015-16 and 0.4 in 2018-19. Finally, in Appendix A3 we show that electricity consumption increases with expenditure holding the Electrical Appliance Index constant, consistent with positive intensive effects.

\footnotetext{
${ }^{6}$ Economists have long preferred a money metric of utility in the form of income or consumption (Samuelson, 1974), and consumption has overshadowed income as a measure of welfare at least since the World Bank started the Living Standards Measurement Surveys (LSMS) in the mid-1980s (Deaton, 2003). We use the adult equivalency followed by the Government of Pakistan in setting its poverty line to compute family size: one child equals 0.8 adults. https://www.pbs.gov.pk/content/pakistan-socialand-living-standards-measurement

${ }^{7}$ Median expenditure increases with electricity consumption decile in all cases apart from the $6^{\text {th }}$ decile of the 2018/19 survey round, which is slightly lower than the median value in the $5^{\text {th }}$ decile.
} 
Figure 2. Household Electricity consumption \& expenditure per capita in urban Pakistan

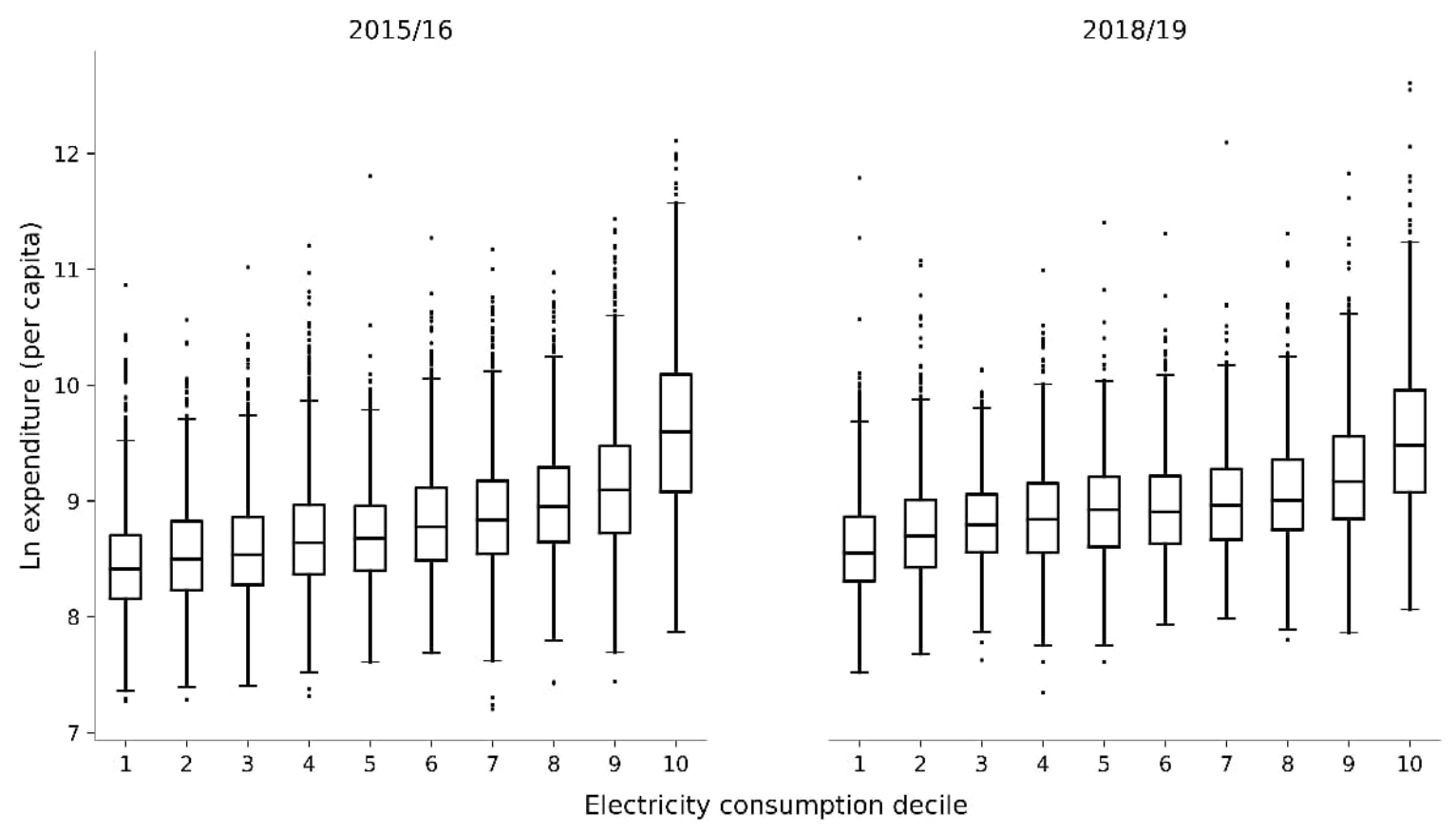

In sum, there is a strong association between electricity consumption, electrical appliance ownership and household expenditure. Given that household expenditure is a well-established and robust indicator of living standards, electricity consumption data may serve as a useful proxy indicator. However, measuring energy consumption with household surveys is costly, time-consuming and does not provide spatially explicit data at sufficient resolution to inform urban planning and policy making within individual settlements. Moreover, expenditure data from surveys can introduce measurement errors (see below) that can be avoided with direct observation of energy consumption. As an alternative to household surveys, we examine the potential of two alternative sources of energy data to generate proxy estimates for living standards within cities: residential electricity meters and night lights.

\section{Data \& methods}

\section{Establisbing blocks as spatial units for analysis}

To generate areal estimates of living standards we need a spatial unit for analysis. When using administrative or survey data this would usually be an enumeration area; when using remotely sensed data such as satellite imagery this is often a grid cell. However, enumeration areas are drawn for statistical convenience in cities (e.g., containing roughly equivalent populations) rather than to reflect real social or economic geographies, and people don't live in grid cells. People live in blocks and neighbourhoods of varying size and shape. While the boundaries of neighbourhoods are fuzzy and subjective (Poorthuis, 2018), it is a stylized fact that people living close together tend to be similar due to a combination of economic forces, social preferences, public policies and planning practices (Clark, 1991; Clark \& Fossett, 2008; Glaeser et al., 2009; Logan, 2012; Schelling, 1971; Tobler, 1970; York et al., 2011). It has also been shown that urban infrastructure such as roads, railways, canals and open spaces serve as natural boundaries between neighbourhoods and communities (Grannis, 1998, 2005; Tóth et al., 2019). 
Building on these insights, we create spatial units that approximate blocks and neighbourhoods that conform to readily observable natural boundaries. This 'organic' geometry has more substantive analytic and practical value for planners and policy makers than either enumeration areas or standard grids superimposed on the urban landscape. For convenience we refer to these spatial units as 'blocks' despite the fact that many are comprised of more than one city block as traditionally understood. To generate these blocks, we start by defining the outer boundary of the city with reference to the formal administrative boundaries (urban subdivisions of Karachi District). However, in many places the actual built-up area has 'spilled' across these formal boundaries, resulting in a mismatch between the urban-administrative and physical boundaries of the city. High resolution satellite imagery was used to edit the administrative base map to incorporate the built-up areas that cross formal boundaries. Where possible, we used visible infrastructure (e.g. roads and rivers) as boundaries for these extra-administrative settlements. We did not include non-contiguous satellite settlements. The outer edge of our study area therefore corresponds to the formal administrative boundaries adjusted for contiguous urban expansion. This is important from a planning and policy point of view: in rapidly growing cities with many poor communities on the periphery, understanding conditions within this de facto boundary can change important planning and resource allocation decisions.

We use infrastructure and land use classification data from Open Street Map (OSM) to generate the blocks that form our fundamental spatial units. Roads, canals, railways, and open spaces were treated as natural boundaries between blocks. Lands classified as non-residential areas were generally excluded (e.g. industrial parks, university campuses, military installations, airports, etc). However, some of these lands contained electricity meters indicating the presence of residences. To account for this, based on the assumption that our meter data are more likely to be accurate than the OSM data, these exclusion zones were gridded into $100 \mathrm{~m} * 100 \mathrm{~m}$ cells. Cells that contained meters were retained as part of the blocks, those without meters were excluded.

To ensure anonymity of individual households, given the potentially sensitive and disclosive nature of the data, blocks were spatially aggregated such that each final block contains a minimum of five residential meter observations. The final map contains 45,081 blocks with five or more observations. These blocks range in size depending on urban spatial structure, the accuracy of the OSM data, and the number of meters in each neighbourhood (see Table 1). Many of the larger blocks contain a mix of industrial and residential uses. Appendix B provides full details of the procedure for generating the base map from these data.

\section{Electricity and night lights data}

Each block is classified into an energy consumption decile using two different sources of data. First, we use data on residential electricity consumption provided by K-Electric (KE), the monopoly provider of electricity in Karachi. The data consist of average kilowatt hours $(\mathrm{kw} / \mathrm{h})$ of electricity consumed per month per meter between 1 April 2019 to 31 March 2020. The raw data included 2.5 million residential meters in Karachi and surrounding rural areas. Observations falling outside of the urban boundary were discarded $(313,446)$ leaving a sample of roughly 2.08 million. Of these, 136,088 negative values were treated as anomalies and discarded, along with all values between 0 and $1(34,246)$. Values between 0 and 1 were dropped to eliminate plausibly unoccupied properties. A single unit of consumption translates into roughly 30 hours of use of a standard lightbulb in a month, which we take as a reasonable lower threshold. The final sample consists of $2,048,418$ observations.

We have a high degree of confidence that these data cover the overwhelming majority of households in Karachi. According to World Bank Development Indicators (accessed 8 March 2021) 100\% 
of Pakistan's urban population has access to electricity. Of the 8622 urban respondents to the 2018/19 HIES survey $98.11 \%$ reported having access to electricity from the grid. An independent survey conducted in one district in Karachi $2018(\mathrm{n} \approx 1000)$ found that $96 \%$ of respondents received electricity bills each month (Haider, 2020, p. 85). Importantly, the same study found that many people do not pay their bills regularly, resulting in bills that do not necessarily reflect actual consumption for any given time period (ibid, p. 119). This makes billing data a less reliable source of information on electricity consumption than observed kilowatt hours consumed.

We calculated the mean, median and standard deviation of average monthly electricity consumption for all meters in each block (Table 1). Consumption decile thresholds were calculated from the cleaned KE meter data and each block was classified into a decile based on the median meter value within that block. Results are reported in deciles as we are primarily interested in relative living standards with clear thresholds-standard practice in living standards measurement for policy applications. This approach also strengthens privacy protections by expanding the range of potential values that could theoretically be attributed to any individual household within a block. More precise point estimates could be used for specific research or policy applications (e.g. to monitor marginal changes in local welfare due to an economic shock). However, given the potentially disclosive nature of this type of data, great care is required in the reporting of such analysis to ensure maximum privacy.

The residential electricity pricing structure is fixed in Pakistan, thereby eliminating potential biases associated with variation in price elasticities of demand across the city. While the decile thresholds calculated from the KE data are slightly different from those derived from the HIES data, there is a very close correspondence (see Appendix B). The difference can be attributed to (a) distinct populations (i.e. all urban Pakistan vs just Karachi) and different approaches to measurement (i.e. inference from expenditure data vs direct observation of $\mathrm{kw} / \mathrm{h}$ consumed).

Table 1. Descriptive statistics for blocks

\begin{tabular}{|c|c|c|c|c|c|c|c|}
\hline & Min & Max & Mean & Std & $\begin{array}{l}1 \text { st } \\
\text { Quartile }\end{array}$ & Median & $\begin{array}{l}\text { 3rd } \\
\text { Quartile }\end{array}$ \\
\hline Block size $\left(\mathrm{km}^{2}\right)$ & 0.00006 & 16.65 & 0.02 & 0.18 & 0.002 & 0.004 & 0.008 \\
\hline KE meter count & 5 & 6879 & 46 & 87 & 14 & 26 & 48 \\
\hline Median consumption (kw/h) & 1 & 2922 & 243 & 146 & 167 & 209 & 269 \\
\hline Nightlight average radiance & 0 & 125 & 41 & 18 & 28 & 38 & 52 \\
\hline
\end{tabular}

There are limitations to this data, which are common in cities in many LMICs. While access coverage is generally comprehensive, illegal connections and sharing of connections (legal and illegal) are not uncommon and can lead to biased estimates. We are also unable to account for family size and composition, which can affect consumption patterns. Where relatively accurate population figures are available at small spatial scales, these unknowns could be partially accounted for, but this is rarely the case. Electricity consumption data are also likely to miss the most marginalised individuals and groups, who may have no access at all. Lastly, meters are not always located within the dwelling with which they are associated - there are meter junctions in some areas-limiting the extent to which a meter can be associated with a specific household or collection of households. Nevertheless, there are few other sources that provide the scale and spatial granularity of residential electricity consumption data, making it an attractive source for generating rough areal estimates of relative living standards in urban areas. 
One potential and readily available alternative is night lights data. To determine if such data could be similarly used as proxy for energy consumption at block or neighbourhood scale, we processed data from the Visible Infrared Radiometer Suite (VIIRS) from NASA. While data from the Defense Meteorological Satellite Program (DMSP) has been used much more widely as a proxy for subnational economic activity in the past, Gibson et al. (2021) show that it provides significantly inferior GDP estimates at high spatial resolution compared to VIIRS, particularly in urban areas. To match the VIIRS data as closely as possible to the KE data, we used average monthly luminosity values from 2019 from the Annual VNL V2 product, which has a spatial resolution of $500 \mathrm{~m}^{2}$ (Elvidge et al., 2021). Median night light radiance values were calculated for each block in the base map, and each block was then assigned a luminosity decile.

\section{Results: Spatial estimates of living standards in Karachi}

Figure 3 compares the spatial distribution of median electricity consumption and luminosity for every block in Karachi. While there is broad correspondence in some central areas, there are also notable differences that illustrate the limitations of using VIIRS data as a proxy for living standards within cities.

Area A shows a peninsula in Karachi South that contains diverse neighbourhoods. The southeastern section contains a neighbourhood known as Clifton—one of the wealthiest in the city. On the north-west side are a collection of much poorer settlements adjacent to major port facilities. The block-level estimates from the KE data reflect these socioeconomic geographies while the luminosity data would miss-classify Clifton as one of the poorest areas of the city and some of the poorer neighbourhoods as relatively wealthy. Area B encompasses the old city centre close to the commercial port, including areas such as Lyari, which is one of the most densely populated neighbourhoods in the city and contains a mix of poor, middle and upper-middle income residents. Again, the KE data reflect this diversity while the luminosity data would rank this as one of the wealthier parts of the city. Finally, area $C$ on the map contains Malir Cantonment-an area that contains both a military base and a civilian residential area that has some of the most expensive property prices in the city. Electricity consumption reflects this affluence while luminosity does not.

Figure 4 shows the block-level correlation between the natural log of electricity consumption and the natural $\log$ of luminosity. The correlation is weakly positive but explains only a small fraction of variation in the observed residential consumption $\left(\mathrm{r}^{2}=.105\right)$. A similar comparison with a gridbased approach aggregated to the native VIIRS resolution of $500 \mathrm{~m}^{2}$ yields a similar result (see Appendix C). Overall, these results confirm that luminosity data are a poor proxy for residential energy consumption in the city. 
Figure 3. Spatial comparison of median electricity consumption and luminosity by block in Karachi (deciles)

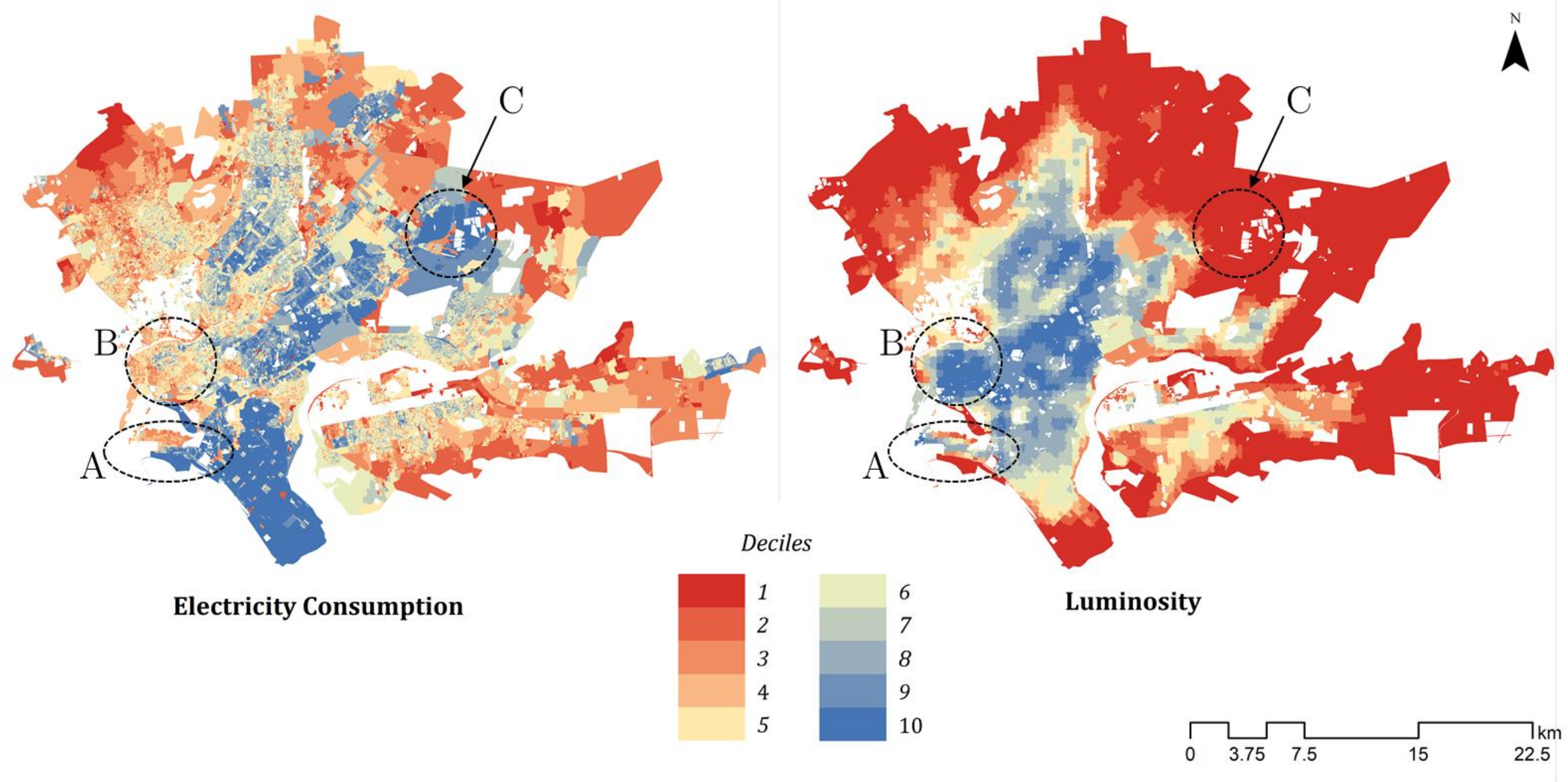


Figure 4. Block-level correlation between electricity consumption and luminosity
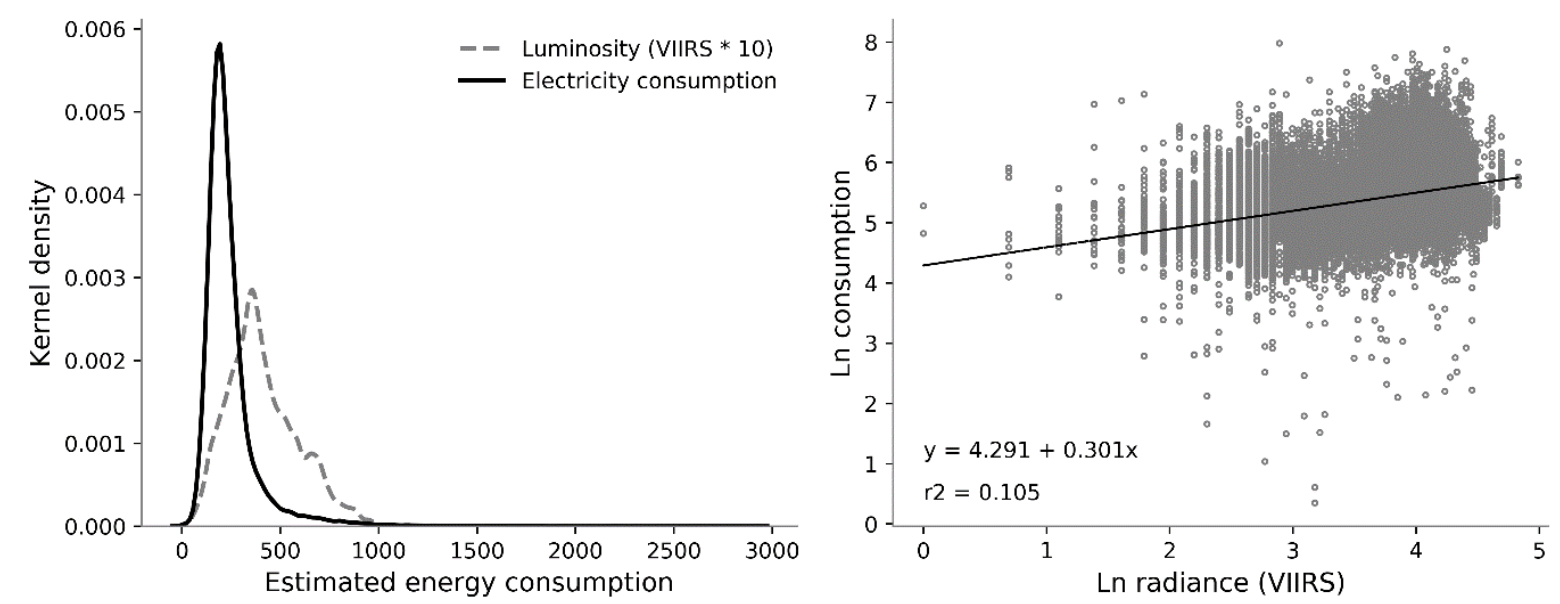

The likely explanation for these discrepancies relates to the nature of the information that luminosity data provide. While often used as a proxy for GDP or 'economic activity' in general, luminosity data are also used to model population distributions (Chen \& Nordhaus, 2011; Sutton et al., 2001). While reliable population statistics are not available at high spatial resolution in Karachi, we find that residential meter count per block (a proxy for population density) is more strongly correlated with luminosity $\left(\mathrm{r}^{2}=.234\right)$ than median consumption values. This, alongside the fact that luminosity is also correlated with economic infrastructure such as street lamps industrial facilities (Gibson et al., 2021), explain the discrepancies observed in our three case study areas. The wealthy neighbourhood of Clifton is less densely populated than those directly adj acent to the port; the neighbourhoods captured in area B are some of the most densely populated in the city, and Malir Cantonment (circle $\mathrm{C}$ ) is effectively a wealthy suburb. The VIIRS data may still prove to be a useful proxy for economic activity more broadly in cities, and as an input into population distribution models, but it does not provide spatially accurate estimates of household living standards on its own. However, future research could explore combining luminosity data with other ancillary sources to model living standards within cities.

\section{Discussion \& Conclusion}

Residential electricity consumption data could serve as a valuable proxy for living standards in urban areas where other sources of data are unavailable. We have also shown that VIIRS night lights data are not suitable for this purpose on their own.

There are clear benefits to using electricity data as a proxy: it has a high spatial resolution and can be collected in real time. These are valuable attributes in rapidly changing cities in LMICs. Timeseries consumption data could be used to address important empirical questions related to urban poverty, inequality, and urban economic development, as well as provide planners and policy makers with spatially explicit information about living standards in real time. Indeed, this research project was initiated in an effort to provide information on the spatial distribution of urban poverty within the context of the COVID crisis in the absence of alternative sources.

Even accounting for measurement error associated with electricity theft, meter sharing and alternative fuel use, there are few sources of data that can match the spatial coverage of electricity data 
at such minimal cost. In cities where georeferenced household meter data are not available, or where the proportion of illegal connections is very high, data from transformers (which typically service between $\sim 50-150$ households) could be used in conjunction with population estimates or ancillary data such as satellite imagery to generate similar small-area estimates of living standards.

There are clear obstacles to accessing and using electricity data. It is potentially disclosive and often proprietary. However, non-commercial research partnerships with public and private providers of electricity could rapidly improve our ability to measure and monitor energy poverty and living standards in urban areas in LMICs. 


\section{References}

Baker, J., \& Schuler, N. (2004). Analyzing Urban Poverty: A Summary of Methods and Approaches (No. 3399; Policy Research Working Papers). The World Bank. https://doi.org/10.1596/18139450-3399

Bernard, T. (2012). Impact Analysis of Rural Electrification Projects in Sub-Saharan Africa. The World Bank Research Observer, 27(1), 33-51. https://doi.org/10.1093/wbro/lkq008

Burki, A. A., Memon, R., \& Mir, K. (2015). Multiple Inequalities and Policies to Mitigate Inequality Traps in Pakistan.

Cao, J., Ho, M. S., Li, Y., Newell, R. G., \& Pizer, W. A. (2019). Chinese residential electricity consumption: Estimation and forecast using micro-data. Resource and Energy Economics, 56, 627. https://doi.org/10.1016/j.reseneeco.2017.10.003

Carr-Hill, R. (2013). Missing Millions and Measuring Development Progress. World Development, 46, 30-44. https://doi.org/10.1016/j.worlddev.2012.12.017

Chen, X., \& Nordhaus, W. D. (2011). Using luminosity data as a proxy for economic statistics. Proceedings of the National Academy of Sciences of the United States of America, 108(21), 8589-8594. https://doi.org/10.1073/pnas.1017031108

Clark, W. A. V. (1991). Residential preferences and neighborhood racial segregation: A test of the schelling segregation model. Demography, 28(1), 1-19. https://doi.org/10.2307/2061333

Clark, W. A. V., \& Fossett, M. (2008). Understanding the social context of the Schelling segregation model. Proceedings of the National Academy of Sciences of the United States of America, 105(11), 4109-4114. https://doi.org/10.1073/pnas.0708155105

De Martino Jannuzzi, G., \& Schipper, L. (1991). The structure of electricity demand in the Brazilian household sector. Energy Policy, 19(9), 879-891. https://doi.org/10.1016/03014215(91)90013-E

Deaton, A. (2003). Household surveys, consumption, and the measurement of poverty. Economic Systems Research, 15(2), 135-159. https://doi.org/10.1080/0953531032000091144

Dinkelman, T. (2011). The effects of rural electrification on employment: New evidence from South Africa. American Economic Review, 101(7), 3078-3108. https://doi.org/10.1257/aer.101.7.3078

Elbers, C., Fujii, T., Lanjouw, P., Özler, B., \& Yin, W. (2007). Poverty alleviation through geographic targeting: How much does disaggregation help? Journal of Development Economics, 83(1), 198-213. https://doi.org/10.1016/j.jdeveco.2006.02.001

Elvidge, C. D., Zhizhin, M., Ghosh, T., Hsu, F.-C., \& Taneja, J. (2021). Annual Time Series of Global VIIRS Nighttime Lights Derived from Monthly Averages: 2012 to 2019. Remote Sensing, 13(5), 922. https://doi.org/10.3390/rs13050922

Filippini, M., \& Pachauri, S. (2004). Elasticities of electricity demand in urban Indian households. Energy Policy, 32(3), 429-436. https://doi.org/10.1016/S0301-4215(02)00314-2

Gertler, P. J., Shelef, O., Wolfram, C. D., \& Fuchs, A. (2016). The demand for energy-using assets among the world's rising middle classes. American Economic Review, 106(6), 1366-1401. 
https://doi.org/10.1257/aer.20131455

Gibson, J., Olivia, S., Boe-Gibson, G., \& Li, C. (2021). Which night lights data should we use in economics, and where? Journal of Development Economics, 102602. https://doi.org/10.1016/j.jdeveco.2020.102602

Glaeser, E. L., Resseger, M., \& Tobio, K. (2009). INEQUALITY IN CITIES. Journal of Regional Science, 49(4), 617-646. https://doi.org/10.1111/j.1467-9787.2009.00627.x

González-Eguino, M. (2015). Energy poverty: An overview. In Renewable and Sustainable Energy Reviews (Vol. 47, pp. 377-385). Elsevier Ltd. https://doi.org/10.1016/j.rser.2015.03.013

Grannis, R. (1998). The importance of trivial streets: Residential streets and residential segregation. American Journal of Sociology, 103(6), 1530-1564. https://doi.org/10.1086/231400

Grannis, R. (2005). T-Communities: Pedestrian Street Networks and Residential Segregation in Chicago, Los Angeles, and New York. City \& Community, 4(3), 295-321. https://doi.org/10.1111/j.1540-6040.2005.00118.x

Grogan, L., \& Sadanand, A. (2013). Rural Electrification and Employment in Poor Countries: Evidence from Nicaragua. World Development, 43, 252-265. https://doi.org/10.1016/j.worlddev.2012.09.002

Haider, E. A. (2020). Disempowered: Electricity, Citizenship, and the Politics of Privatization in South Asia [Georgetown University]. In Georgetown University-Graduate School of Arts \& Sciences. https://repository.library.georgetown.edu/handle/10822/1060530

Hanna, R., \& Oliva, P. (2015). Moving up the energy ladder: The effect of an increase in economic well being on the fuel consumption choices of the poor in India. American Economic Review, 105(5), 242-246. https://doi.org/10.1257/aer.p20151097

Henderson, J. V., Storeygard, A., \& Weil, D. N. (2012). Measuring economic growth from outer space. In American Economic Review (Vol. 102, Issue 2, pp. 994-1028). https://doi.org/10.1257/aer.102.2.994

Henderson, V., Storeygard, A., \& Weil, D. N. (2011). A bright idea for measuring economic growth. American Economic Review, 101(3), 194-199. https://doi.org/10.1257/aer.101.3.194

Lee, K., Miguel, E., \& Wolfram, C. (2020a). Experimental Evidence on the Economics of Rural Electrification. Journal of Political Economy, 128(4), 1523-1565. https://doi.org/10.1086/705417

Lee, K., Miguel, E., \& Wolfram, C. (2020b). Does household electrification supercharge economic development? In Journal of Economic Perspectives (Vol. 34, Issue 1, pp. 122-144). American Economic Association. https://doi.org/10.1257/JEP.34.1.122

Logan, J. R. (2012). Making a place for space: Spatial thinking in social science. In Annual Review of Sociology (Vol. 38, pp. 507-524). Annual Reviews . https://doi.org/10.1146/annurev-soc071811-145531

Lucci, P., Bhatkal, T., \& Khan, A. (2018). Are we underestimating urban poverty? World Development, 103, 297-310. https://doi.org/10.1016/j.worlddev.2017.10.022

MQM-P seeks SC directive for fresh census in Sindh - Pakistan - DAWN.COM. (2020, October 23). Dawn. https://www.dawn.com/news/1586530

Nawaz, S., \& Iqbal, N. (2020). The impact of unconditional cash transfer on fuel choices among 
ultra-poor in Pakistan: Quasi-experimental evidence from the Benazir Income Support Program. Energy Policy, 142, 111535. https://doi.org/10.1016/j.enpol.2020.111535

Nussbaumer, P., Bazilian, M., \& Modi, V. (2012). Measuring energy poverty: Focusing on what matters. In Renewable and Sustainable Energy Reviews (Vol. 16, Issue 1, pp. 231-243). Elsevier Ltd. https://doi.org/10.1016/j.rser.2011.07.150

Onda, K., Sinha, P., Gaughan, A. E., Stevens, F. R., \& Kaza, N. (2019). Missing millions: undercounting urbanization in India. Population and Environment, 41(2), 126-150. https://doi.org/10.1007/s11111-019-00329-2

Poorthuis, A. (2018). How to Draw a Neighborhood? The Potential of Big Data, Regionalization, and Community Detection for Understanding the Heterogeneous Nature of Urban Neighborhoods. Geographical Analysis, 50(2), 182-203. https://doi.org/10.1111/gean.12143

Ravallion, M., Chen, S., \& Sangraula, P. (2007). New Evidence on the Urbanization of Global Poverty. Population and Development Review, 33(4), 667-701. https://doi.org/10.1111/j.17284457.2007.00193.x

Sakah, M., de la Rue du Can, S., Diawuo, F. A., Sedzro, M. D., \& Kuhn, C. (2019). A study of appliance ownership and electricity consumption determinants in urban Ghanaian households. Sustainable Cities and Society, 44, 559-581. https://doi.org/10.1016/j.scs.2018.10.019

Samuelson, P. A. (1974). Complementarity: An Essay on the 40th Anniversary of the HicksAllen Revolution in Demand Theory. Journal of Economic Literature1, 12(4), 1255-1289.

Schelling, T. C. (1971). Dynamic models of segregation. The Journal of Mathematical Sociology, 1(2), 143-186. https://doi.org/10.1080/0022250X.1971.9989794

Sutton, P., Roberts, D., Elvidge, C., \& Baugh, K. (2001). Census from Heaven: An estimate of the global human population using night-time satellite imagery. International Journal of Remote Sensing, 22(16), 3061-3076. https://doi.org/10.1080/01431160010007015

Tobler, W. R. (1970). A Computer Movie Simulating Urban Growth in the Detroit Region. Economic Geography, 46, 234. https://doi.org/10.2307/143141

Tóth, G., Wachs, J., Clemente, R. Di, Jakobi, Á., Ságvári, B., Kertész, J., \& Lengyel, B. (2019). Inequality is rising where social network segregation interacts with urban topology. In arXiv (Vol. 12, Issue 1, pp. 1-9). arXiv. https://doi.org/10.1038/s41467-021-21465-0

United Nations, Department for Economic and Social Affairs, P. D. (2018). World Urbanization Prospects: The 2018 Revision. In Demographic Research (Online Edi, Vol. 12). https://population.un.org/wup/Publications/Files/WUP2018-Report.pdf

Van Der Kroon, B., Brouwer, R., \& Van Beukering, P. J. H. (2013). The energy ladder: Theoretical myth or empirical truth? Results from a meta-analysis. In Renewable and Sustainable Energy Reviews (Vol. 20, pp. 504-513). Elsevier Ltd. https://doi.org/10.1016/j.rser.2012.11.045

Wolfram, C., Shelef, O., \& Gertler, P. (2012). How will energy demand develop in the developing world? Journal of Economic Perspectives, 26(1), 119-138. https://doi.org/10.1257/jep.26.1.119

World Bank. (2017). State of electricity access report 2017 (Vol. 2) : full report (English). http://documents.worldbank.org/curated/en/364571494517675149/full-report 
Ye, Y., Koch, S. F., \& Zhang, J. (2018). Determinants of household electricity consumption in South Africa. Energy Economics, 75, 120-133. https://doi.org/10.1016/j.eneco.2018.08.005

York, A. M., Smith, M. E., Stanley, B. W., Stark, B. L., Novic, J., Harlan, S. L., Cowgill, G. L., \& Boone, C. G. (2011). Ethnic and Class Clustering through the Ages: A Transdisciplinary Approach to Urban Neighbourhood Social Patterns. Urban Studies, 48(11), 2399-2415. https://doi.org/10.1177/0042098010384517

Zhou, S., \& Teng, F. (2013). Estimation of urban residential electricity demand in China using household survey data. Energy Policy, 61, 394-402.

https://doi.org/10.1016/j.enpol.2013.06.092 


\section{Appendix A}

\section{A1. Electrical Appliance Ownership Index}

The 2018/19 HIES contains information on (a) appliances possessed in the last month and (b) appliances possessed in the last one year. Since the electricity expenditure data is available for the last one month, we use (a) to construct our index. Individually, washing machines, televisions and refrigerators are the most common appliances owned by households in the lowest deciles, with ownership of other appliances only increasing significantly after the sixth consumption decile. Although we do not observe a tapering off in the highest decile, this is likely due to sample bias: it is difficult to conduct surveys in richer neighbourhoods, which truncates the income/expenditure distribution at the higher deciles (Burki et al., 2015). Indeed, we do find that the estimated marginal effect of per capita expenditure at very high levels of expenditure is statistically indistinguishable at different (high) levels of appliance ownership. To construct an index we weighted each appliance by the intensity of usage. Data on an appliances' energy consumption were gleaned from several website:

(1) This site provided a list of appliances with different usages. We chose the energy consumption of the median appliance to serve as weights: https://savejoules.com/refrigerator-brands.html

(2) This site was used for microwaves and irons: https://energyusecalculator.com/electricity microwave.htm

(3) This site was used to construct relative weights of air coolers: https://www.bijlibachao.com/air-conditioners/desert-air-coolers-better-option-than-air-conditioners-for-hot-and-dry-places.html

The latter site was the most informal. However, air coolers are ubiquitous in lower middle-income classes in Pakistan and should not be ignored. But since these appliances are often made in small workshops rather than large factories, power ratings were difficult to come by. The final weights in estimated KWh per month are presented in the table below.

Table A.1 Electrical Appliances and their expected power consumption

\begin{tabular}{lcc}
\hline Electrical Appliances & $\begin{array}{c}\text { Electricity Usage (KWh per } \\
\text { month) }\end{array}$ & Expected Usage (hours per day) \\
\hline Television (CRT/ Flat Screen) & 11 & 3 \\
Fridge & 73 & 24 \\
Freezer & 65 & 24 \\
Washing Machine & 31 & 1.5 \\
Air Conditioner & 127 & 8 \\
Air cooler & 21 & 8 \\
Fan & 22 & 10 \\
Microwave & 18 & 0.5 \\
Iron & 15 & 0.5 \\
\hline
\end{tabular}

\section{A2. Tariff Rates and the Construction of Household Units of Consumption}

The HIES surveys contain information on electricity expenditure in the month before the survey. We estimated units of electricity consumed by using the tariff structure announced by the Government of Pakistan in 2015 and 2018 (See Table A2.1). Since information on sales tax on electricity in 2015-16 was not unavailable, consumption was estimated using net expenditures in 2018-19 but gross expenditures in 2015-16. The HIES 2018-2019 began in July 2018 and ended in August 2019, which means the tariff structure changed in the middle of this survey round. However, it was possible to identify which households were surveyed in each year and we used the relevant price structure to estimate unit consumption. The distribution of the sample across different districts is available upon request. Table A2.2 shows the thresholds values for classifying households into electricity consumption deciles for each round of the survey. 
Table A2.1: Tariff Structure announced by Government of Pakistan

\begin{tabular}{lcc}
\hline Tariff Slab & $\begin{array}{c}\text { Tariff Effective June 2015 to } \\
\text { December 2018 (Rs.) }\end{array}$ & $\begin{array}{c}\text { Tariff Effective from January 2018 } \\
\text { (Rs.) }\end{array}$ \\
\hline Up to 50 units & 2.00 & 2.00 \\
0-100 units & 5.79 & 5.79 \\
101-200 units & 8.11 & 8.11 \\
201-300 units & 10.2 & 10.2 \\
301-700 units & 16.00 & 17.6 \\
Above 700 units & 18.00 & 20.7 \\
\hline Source: Table 14 in Supplementary Appendix on Energy - Consumer End Tariff, GOP 2020 pg. 168; Table 14 in \\
Supplementary Appendix on Energy - Consumer End Tariff, GOP 2019 pg. 171-72.
\end{tabular}

Table A2.2: Threshold values for Electricity Consumption (Unit) Deciles

\begin{tabular}{ccccc}
\hline Unit decile & \multicolumn{2}{c}{$2015-16$} & \multicolumn{2}{c}{$2018-19$} \\
\hline 1 & Min & Max & Min & Max \\
\hline 2 & 74.98 & 73.80 & 18.22 & 87.45 \\
3 & 102.90 & 102.37 & 87.59 & 132.66 \\
4 & 123.98 & 123.45 & 133.70 & 153.47 \\
5 & 155.91 & 155.07 & 154.51 & 184.69 \\
6 & 176.67 & 176.15 & 186.45 & 212.65 \\
7 & 197.54 & 231.31 & 213.06 & 229.19 \\
8 & 232.15 & 273.21 & 229.44 & 270.56 \\
9 & 273.88 & 363.05 & 312.89 & 311.71 \\
10 & 365.40 & 3593.80 & 403.54 & 402.81 \\
\hline Source: Authors' calculations. & & & \\
\end{tabular}

\section{A3. Explanatory Power of Electrical Appliance Ownership Index}

A linear regression shows the strong and positive association between our EAI and electricity consumption. We fit the following model:

$$
\text { Units }_{i}=\alpha+\beta \text { Family }_{\text {size }_{i}}+\delta \text { Rooms }_{i}+\gamma \text { Appliance_Index }_{i}+\varepsilon_{i}
$$

\section{Linear regression}

Number of obs $=8,500$

$\mathrm{F}(3,785)=181.83$

Prob $>\mathrm{F}=0.0000$

R-squared $=0.3713$

Root MSE $=126.27$

\begin{tabular}{lrrrrrr}
\hline & Coef. & $\begin{array}{r}\text { Robust Std } \\
\text { Err. }\end{array}$ & $\mathrm{t}$ & $\mathrm{P}>|\mathrm{t}|$ & \multicolumn{2}{c}{$[95 \%$ Conf. Interval] } \\
\hline fam_size & 2.00 & 0.88 & 2.28 & 0.02 & 0.27 & 3.72 \\
rooms & 4.41 & 2.18 & 2.02 & 0.04 & 0.13 & 8.68 \\
asset_index & 0.70 & 0.05 & 14.36 & 0.00 & 0.60 & 0.79 \\
_cons & 70.09 & 6.51 & 10.77 & 0.00 & 57.32 & 82.87 \\
\hline Notes: Authors' estimation & & &
\end{tabular}

Notes: Authors' estimation using HIES 2018-19 Std. Err. adjusted for 786 clusters in psu 
To understand the marginal effect of per capita expenditure at different levels of the asset index, we implement the following regression:

$$
\begin{aligned}
& \text { Electricity Units } \\
& \qquad \begin{aligned}
& \\
& \alpha+\beta \text { Family_Size } \\
& +\delta \text { Rooms }_{i}+\gamma \text { Appliance_Index }_{i} \\
& +\theta \text { Per_Capita_Expenditure } e_{i}+\rho+\text { Appliance_Index }_{i} \\
& * \text { Per_Capita_Expenditure }_{i}+\varepsilon_{i}
\end{aligned}
\end{aligned}
$$

As illustrated in Figure A3.1 the marginal effect of increased expenditure on electricity consumption is positive, and increases in line with the EAI, as expected. In other words, at any given level of electrical appliance ownership there is a positive association between expenditure and electricity consumption (i.e. positive intensive margin).

Figure A.3.1 Marginal Effects of Per Capita Expenditure on Electricity Usage

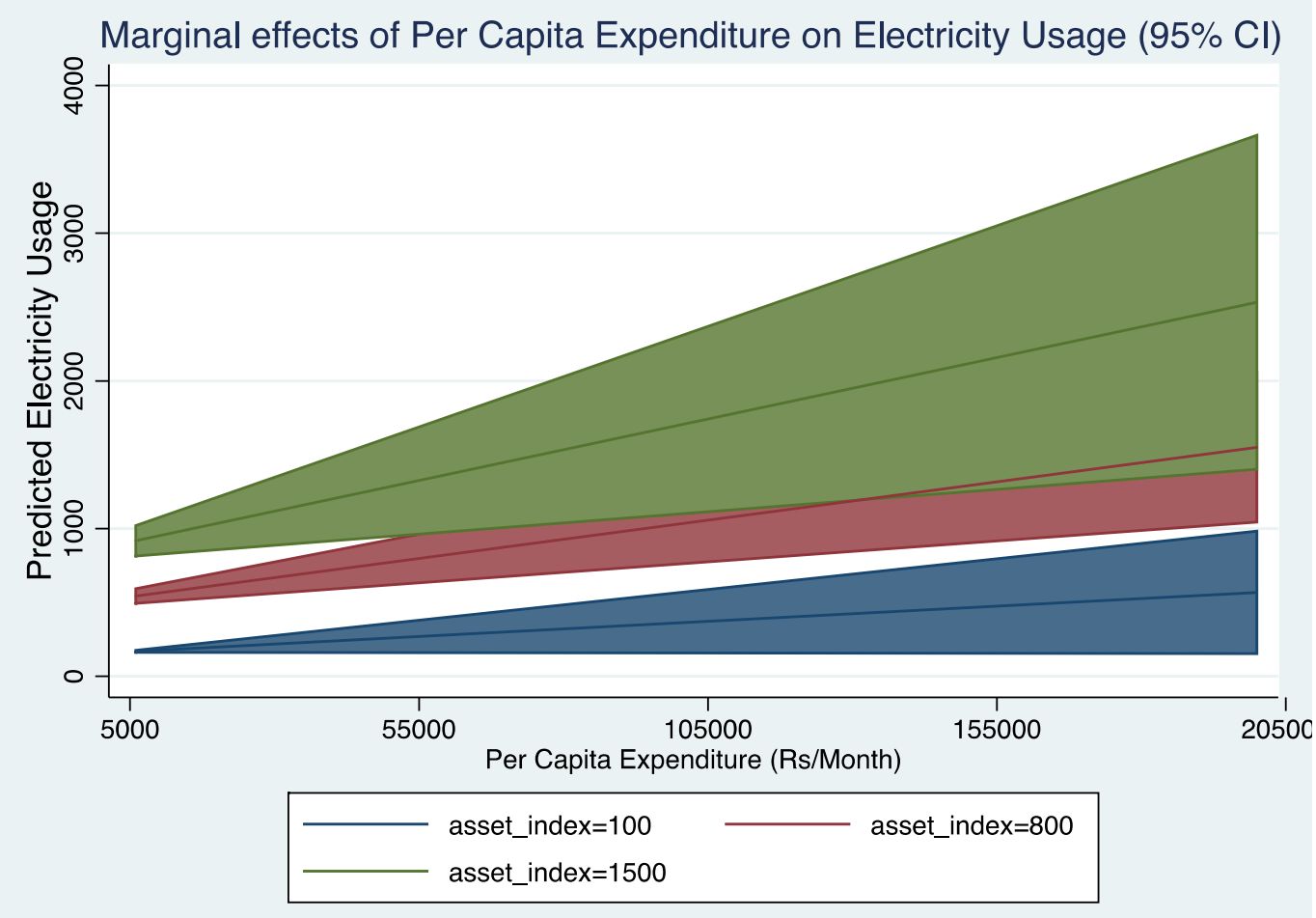




\section{Appendix B: Segmenting Karachi into blocks}

The segmentation was implemented with ArcGIS software version 10.6 using the processes below:

1. The outer boundary of the city was initially drawn with reference to urban administrative boundaries (white lines in Figure B1). This boundary was augmented with visual inspection of ESRI's high-resolution satellite imagery to incorporate contiguous built-up areas and exclude uninhabited major waterways (black lines in Figure B1)

2. Shapefiles of OSM data for Pakistan were accessed from https://download.geofabrik.de/asia.html on 22nd March 2021.

3. Shapefiles were extracted for the study area using the "Clip" tool. The road layer contained some edges that were unconnected to a node.

4. Roads, railways, and waterways were merged into a single layer of linear features using the "Merge" tool.

5. The merged linear features were projected to WGS 1984 UTM Zone 42N Coordinate System using the "Project" tool.

6. Using the "Extend" tool, unconnected edges in the output of step 5 were connected to the nearest node within 100 meters.

7. Used "Feature to Line" tool to convert the outer boundary of the city from polygon to polyline.

8. Merged the outer boundary polyline with the linear features from step 6 using the "Merge" tool.

9. The output of step 8 was polygonised into blocks using "Feature to Polygon" tool.

10. Using "Select by Attributes" tool, non-residential land uses were extracted from the OSM land use layer. These include industrial parks, commercial areas, farms, forest, grass, scrub, recreation ground, orchard, allotment, meadow, and military installations.

11. Created exclusion zones by merging the output of step 10 with OSM polygon layers on places of worship, places of interest, transport areas, traffic areas, and water areas using the "Merge" tool.

12. Projected the output of 11 to WGS 1984 UTM Zone 42N Coordinate System using the "Project" tool.

13. With the output of step 12 as the input features, the "Multipart To Singlepart" tool was used to separate features with multiple polygons into single polygon features.

14. Duplicated polygons from step 13 were removed using the "Delete Identical" tool.

15. Computed the area for each feature from step 14 using "Calculate Geometry" tool in the attribute table.

16. Extracted features with at least $0.01 \mathrm{~km}^{2}$ area as large exclusion zones using the "Select By Attributes" tool. 
17. The exclusion zones from step 16 were gridded into $100 \mathrm{~m} * 100 \mathrm{~m}$ grids using the "Fishnet" and "Clip" tools.

18. Counted the number of residential meters in each exclusion cell from step 17 using the "Spatial Join" tool.

19. Cells with a meter or more were considered as residential areas and subsequently removed from the list of exclusion cells.

20. Extracted the spatial difference between the blocks from step 9 and the exclusion cells from step 19 to generate residential blocks using the "Erase" tool.

21. Counted the number of meters in each residential segment using the "Spatial Join" tool.

22. Selected each residential block with no meters and merged with a neighbour with whom each selected block shares the longest boundary using the "Eliminate" tool.

23. Counted the number of meters in each residential block from step 22 using the "Spatial Join" tool.

24. Selected residential blocks with less than 3 meters and merged each with a neighbour with whom the selected block shares the longest boundary using the "Eliminate" tool.

25. Counted the number of meters in each residential block from the previous step using the "Spatial Join" tool.

26. Selected residential blocks with less than 5 meters and merged each with a neighbour with whom the selected block shares the longest boundary using the "Eliminate" tool.

27. Steps 25 and 26 were repeated several times until it was impossible to spatially merge blocks that contained less than 5 meters. After the fourth repetition, there was a constant of 159 blocks that had less than 5 meters. These were largely isolated slivers with no contiguous neighbours to be merged with. Figure B2 shows the map of before and after aggregation of blocks in a part of the city. 
Figure B1. Outer boundary of Karachi city

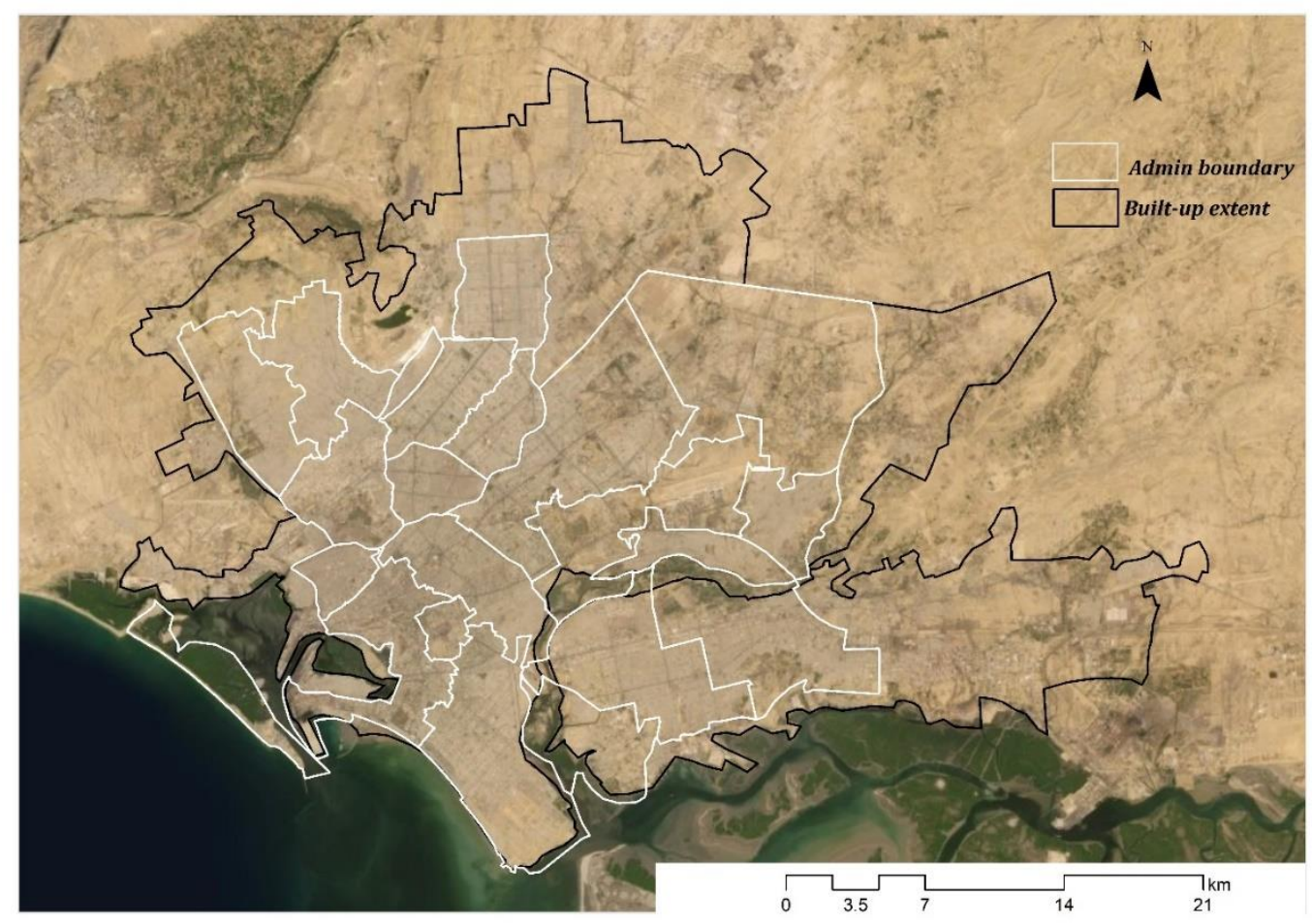

Figure B2. Before and after segment aggregation

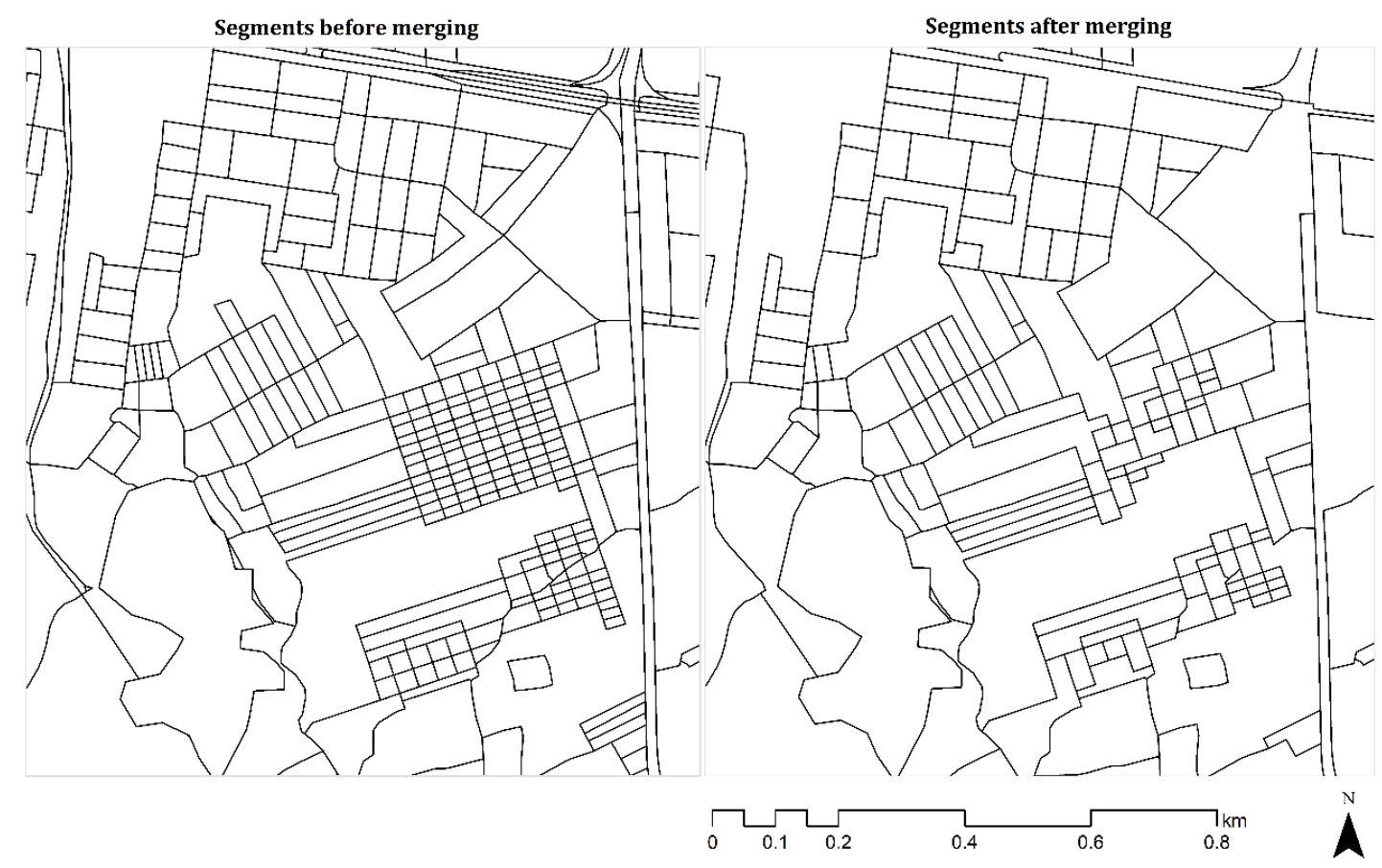


Figure B3. Distribution of residential meter data \& block map of Karachi

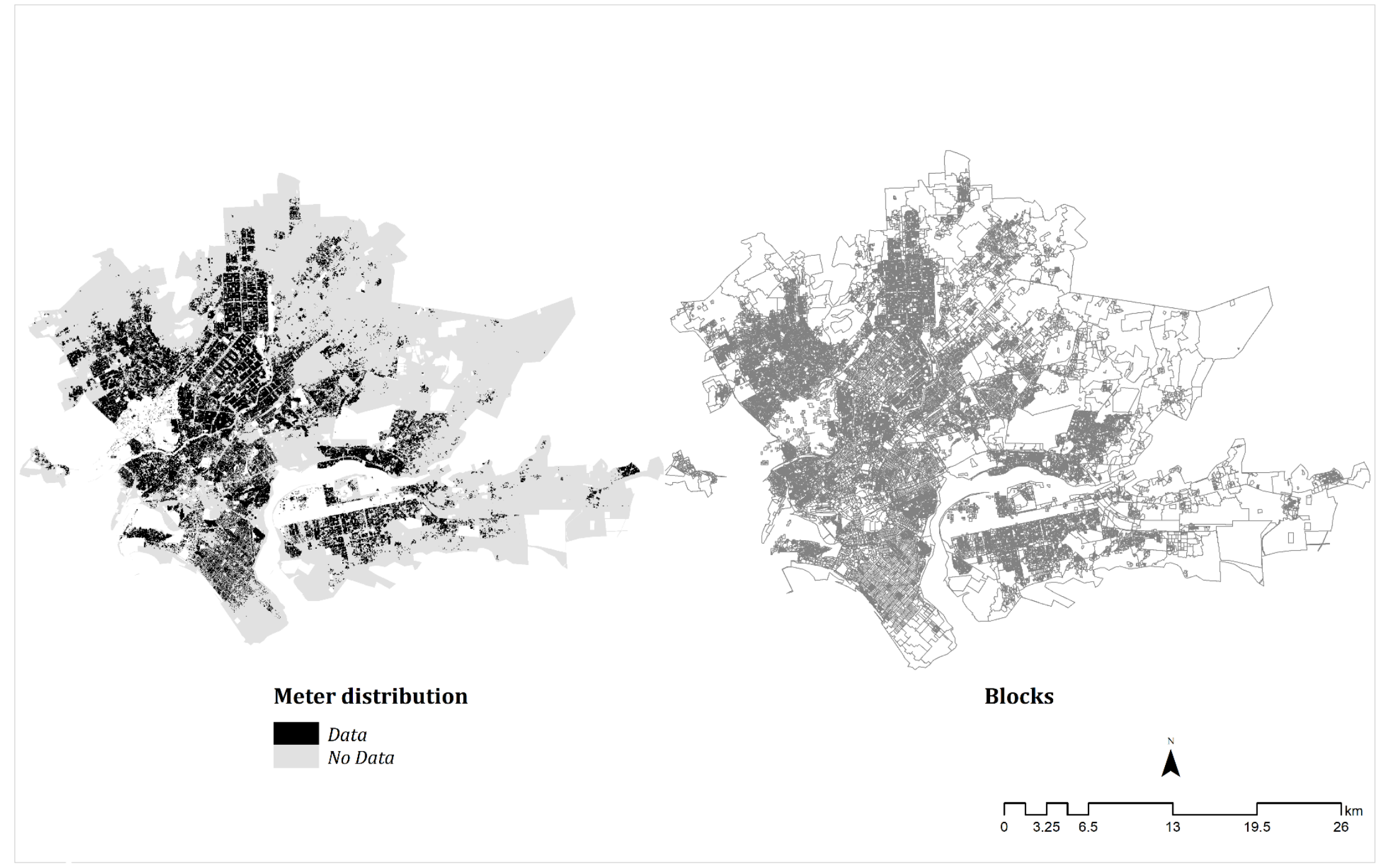




\section{Appendix C: Mapping electricity consumption and luminosity at $500 \mathrm{~m}^{2}$ resolution}

The VIIRS night lights data has a native resolution of $500 \mathrm{~m}^{2}$. To ensure that our key findings are not conditioned by our 'organic' geometry we conducted a sensitivity analysis at the native VIIRS resolution.

The creation of the $500 \mathrm{~m}^{2}$ grid follows the processes outlined in Appendix B. The main difference, however, is that in place of steps 2 to 9, which were used to create blocks, we used the "Fishnet" tool in ArcGIS to generate a grid with regular cell size of $500 \mathrm{~m}^{2}$. Instead of blocks, the generated grid was subsequently used in steps 10 to 26 . At step 27, the final stage, the repetition was done 3 times until there was a constant 158 cells with less than 5 meters. Like the blocks, these cells were isolated patches with no contiguous neighbours. Using the final grid geometry, maps and plots of electricity consumption, luminosity, and meter count were produced (see Figures $\mathrm{C} 1, \mathrm{C} 2$ and $\mathrm{C} 3$ ).

\section{Figure C1. Spatial comparison of median electricity consumption and luminosity by $500 \mathrm{~m}$ grid in Karachi (deciles)}

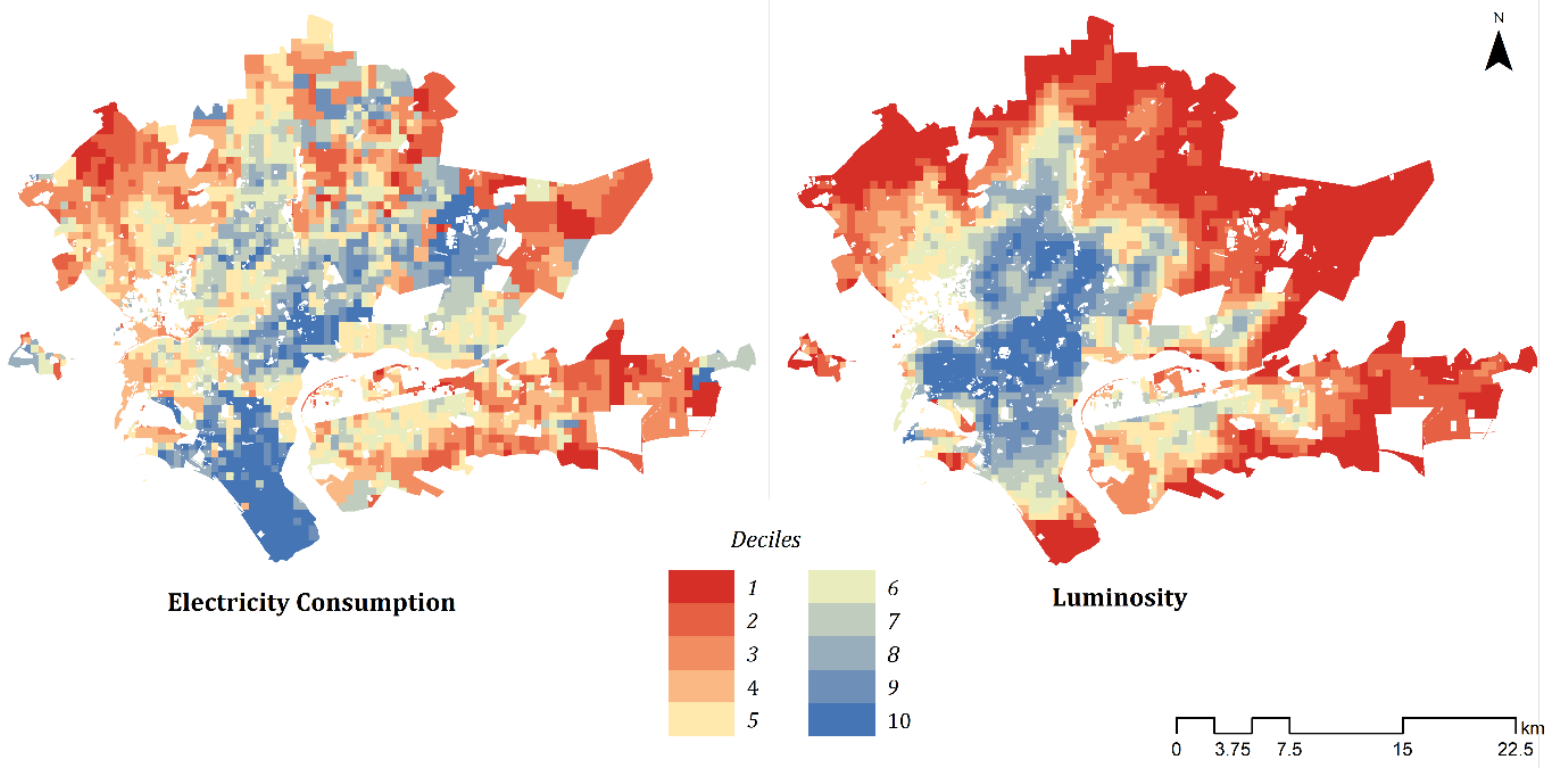

As illustrated in Figure C1, the results are similar and the case study areas highlighted in the paper show an identical pattern of discrepancy between the two data sources. Figure C2 shows that the correlation between median electricity consumption and luminosity is stronger at this resolution, but only marginally so. Finally, $\mathrm{C} 3$ shows that the correlation between luminosity and meter count (a proxy for population density) is substantially stronger, providing some evidence that VIIRS is reflecting population distribution, particularly in the most densely inhabited areas. 
Figure C2. Correlation between median electricity consumption and luminosity $(500 \mathrm{~m}$ grid)
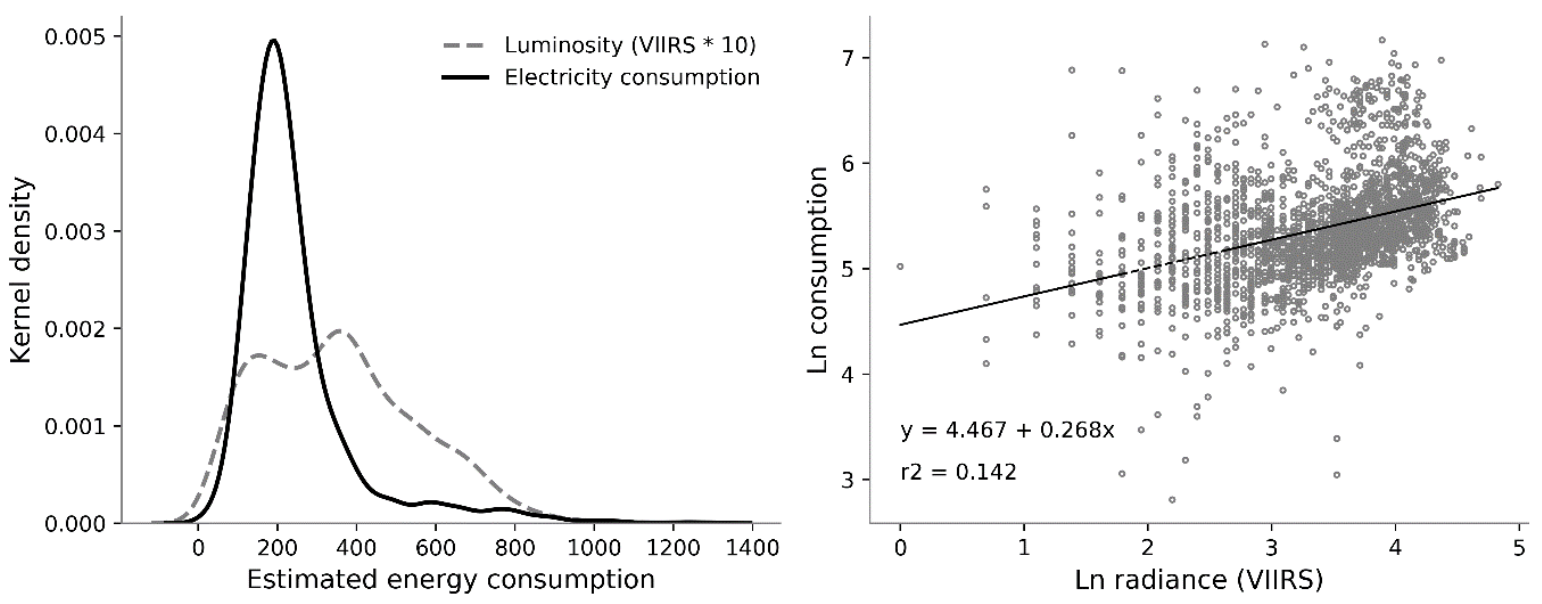

Figure C3. Correlation between meter count and luminosity (500m grid)

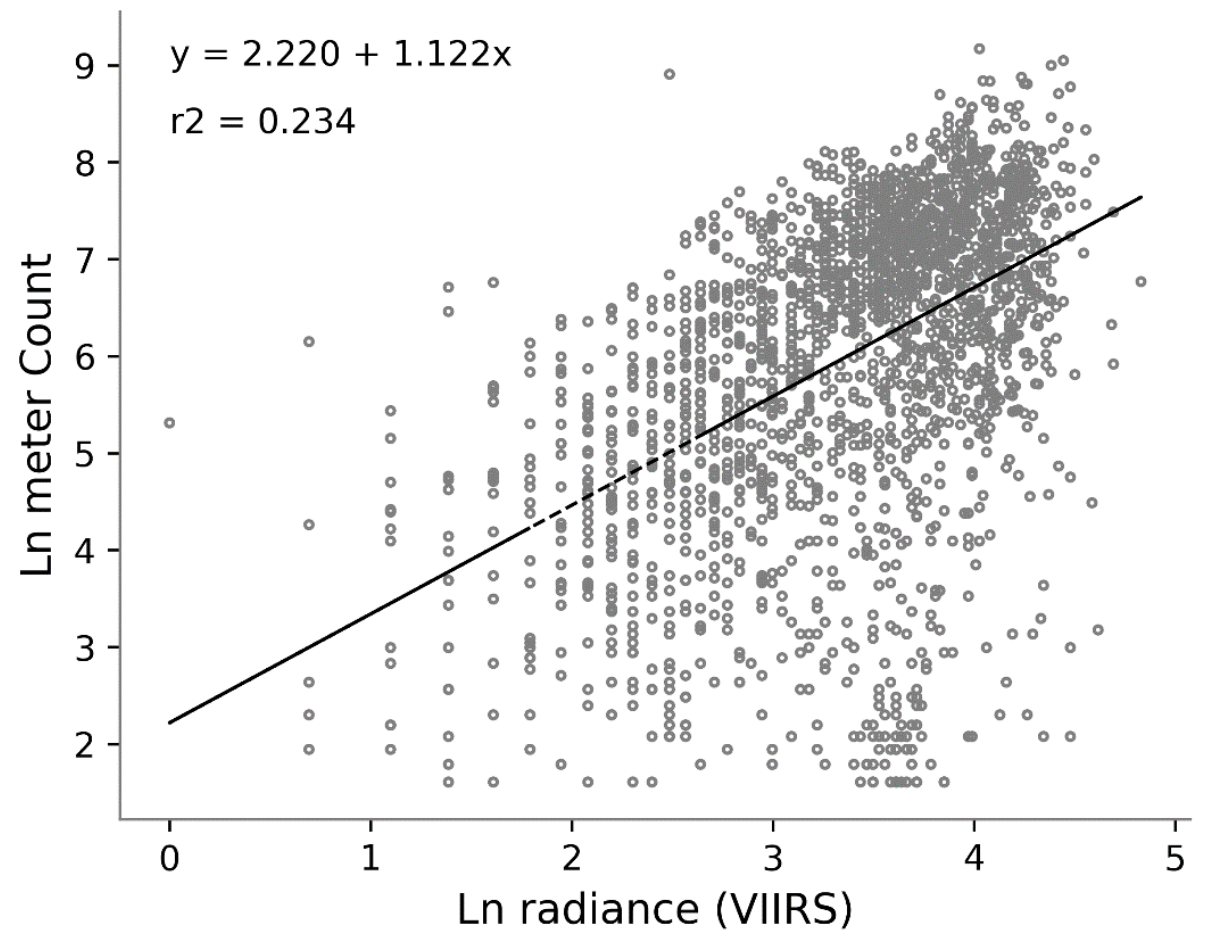

